\title{
Prescribing trends in diabetic neuropathy at a tertiary care hospital
}

\author{
Parvin Banu, Subir Mondal, Arunava Biswas, Syed Mohammed Naser, Mausumi Niyogi \\ Assistant Professor, Department of Anaesthesiology, Calcutta National Medical College, Kolkata, India, $6^{\text {th }}$ Semester \\ MBBS Student, Calcutta National Medical College, Kolkata, India, Assistant Professor, Department of Pharmacology, \\ Calcutta National Medical College, Kolkata, India, Associate Professor, Department of Pharmacology, Bankura \\ Sammilani Medical College, Bankura, India, Professor, Department of Anaesthesiology, Calcutta National Medical \\ College, Kolkata, India
}

A B S TR A C T

Background: Neuropathy, being a common complication of diabetes mellitus is frequently encountered in patients related to duration and severity of hyperglycaemia and had a multimodality treatment approach by the treating physicians. Aims and Objective: To understand and analyze the current drug prescribing trends in the management of diabetic neuropathy in hospitalized and OPD patients in a tertiary care hospital. Materials and Methods: A cross sectional, observational study on $(n=100)$ patients of either sex aged between 18 to 70 years admitted in the Department of Neuromedicine as well as visiting the OPD was conducted for a period of 3 months. Prescriptions were collected and the relevant information i.e. drugs prescribed for diabetic neuropathy only excluding other drugs mentioned in the prescription were documented in a predesigned, pretested proforma and were analyzed. Results: All the prescribed drugs i.e. $(100 \%)$ were oral formulations. The average number of drugs prescribed per prescription for the treatment of diabetic neuropathy including indoor and OPD patients was $3.60 \pm 0.66$. Prescription of single drug for the treatment of diabetic neuropathy was found to be the commonest trend among the prescribers i.e. $78 \%$ of all the prescriptions and they were all in their generic form. Conclusion: Gabapentin and pregablin (antiepileptics), amitryptylline (anti-depressants) and methylcobalamine were most commonly prescribed drugs. Side effects profiles of these drugs were also well evident among the patients. Much larger multicentric studies of similar type including private and public hospitals might reflect the true scenario of current drug prescribing trend among physicians in treating diabetic neuropathy.

Key words: Diabetic neuropathy; prescribing pattern; tertiary hospital

\section{INTRODUCTION}

Peripheral neuropathic pain (PNP) is encountered with increasing frequency in clinical practice, often in conjunction with chronic diseases such as diabetes, HIV infection, multiple sclerosis, cancer, and post-herpes simplex. ${ }^{1}$ Neuropathy, a common complication of diabetes mellitus, is generally considered to be related to duration and severity of hyperglycaemia. However, it may also occur acutely even with hypoglycaemia. ${ }^{2-4}$ Usually more than $50 \%$ of patients with duration of diabetes of 25 years or more are affected, making it as one of the most common disease of the nervous system. ${ }^{4}$ Prevalence of PNP in diabetic patients ranges from around $10.5 \%$ to $32.2 \%$ in various studies across India. ${ }^{5-7}$ The prevalence however, increases progressively without a plateau. Diabetic neuropathy (DN) has been defined as presence of symptoms and/or signs of peripheral nerve dysfunction in diabetics after exclusion of other causes, which may range from hereditary, traumatic, compressive, metabolic, toxic, nutritional, infectious, immune mediated, neoplastic, and secondary to other systemic illnesses. Since the manifestations of diabetic neuropathy closely mimic chronic inflammatory demyelinating polyneuropathy, alcoholic neuropathy, and other endocrine neuropathies, 
hence, before labelling diabetic neuropathy it is mandatory to exclude all other causes of peripheral nerve dysfunction. The study of prescribing patterns is a component of medical audit that monitors and evaluates prescribing practices and recommends necessary modifications to achieve rational drug use. ${ }^{8}$

In carrying out such study valuable information to the researchers, policy makers and the drug and therapeutics committee members to determine the drug use pattern can be provided. ${ }^{9,10}$ Extensive search for similar studies within India revealed that there is a scarcity of data. Therefore, this study was undertaken to understand and analyze the current drug prescribing trend in the management of diabetic neuropathy in hospitalized and OPD patients in a tertiary care hospital.

\section{MATERIALS AND METHODS}

With prior permission from the institutional ethics committee a cross sectional, observational study on $(n=100)$ patients of either sex aged between 18 to $70 \mathrm{yrs}$ admitted in the Department of Neuromedicine as well as visiting the OPD of a tertiary care hospital in Eastern India suffering from diabetic neuropathy were consecutively recruited for a period of 3 months (March-May 2017) in the study. Patients with history of type II diabetes mellitus taking antidiabetic medications suffering from neurological complications like, tingling and numbness, burning sensation of the limbs, low back pain, generalized weakness, ready to give written informed consent were included in the study. Patients critically ill and unable to give consent were excluded.

Prescriptions were collected from the OPDs (outdoor patients' departments) as well as patients admitted in the hospital over a period of three months (March-May 2017). The relevant information i.e. drugs prescribed for diabetic neuropathy only excluding other drugs mentioned in the prescription were documented in a predesigned, pretested proforma and analyzed.

Based on the prevalence of $11.1 \% \mathrm{DN}$ in the eastern part of India ${ }^{11}$ with a confidence level of $95 \%$ and considering a $5 \%$ margin of error the sample size was calculated around $(n=150)$. But within the stipulated time of the project only $n=100$ patients could be recruited for the study. Statistical analysis was done as mean +/- SD and interpreted in tables and charts using Graphpad Instat version 3.06.

\section{RESULTS}

Out of 100 prescriptions analyzed in the study $34 \%$ were from the indoor admitted patients of Neuromedicine department and 66\% were from neurology OPD. A total of 357 numbers of drugs were encountered during the study prescribed only for the treatment of DN. Most of the study patients were female $66 \%$ and were homemakers [Figure 1].

Among the male patients i.e. $33 \%$ mostly they were daily laborers. The average age of the study population was found to be $53.03 \pm 6.70$. The characteristic of symptoms captured during history taking is mentioned in [Table-1].

The average number of drugs prescribed per prescription including indoor and OPD patients was $3.60 \pm 0.66$. All the prescribed drugs i.e. $(100 \%)$ were oral formulations and no parenteral drugs were used during the study. Prescription of single drug for the treatment of $\mathrm{DN}$ was found to be the commonest trend among the prescribers i.e. $78 \%$ of the prescriptions and they were all in generic their form. There were all total 60 encounters with fixed dose

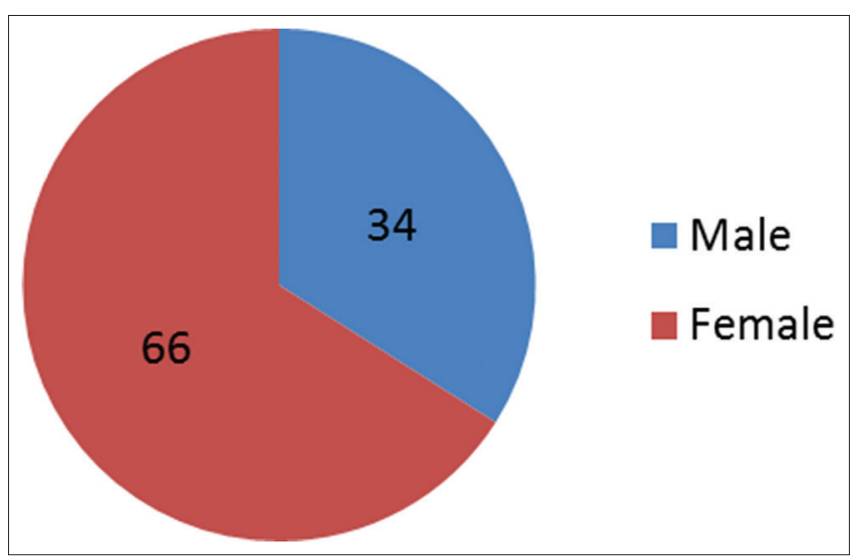

Figure 1: Distribution of gender among the study participants

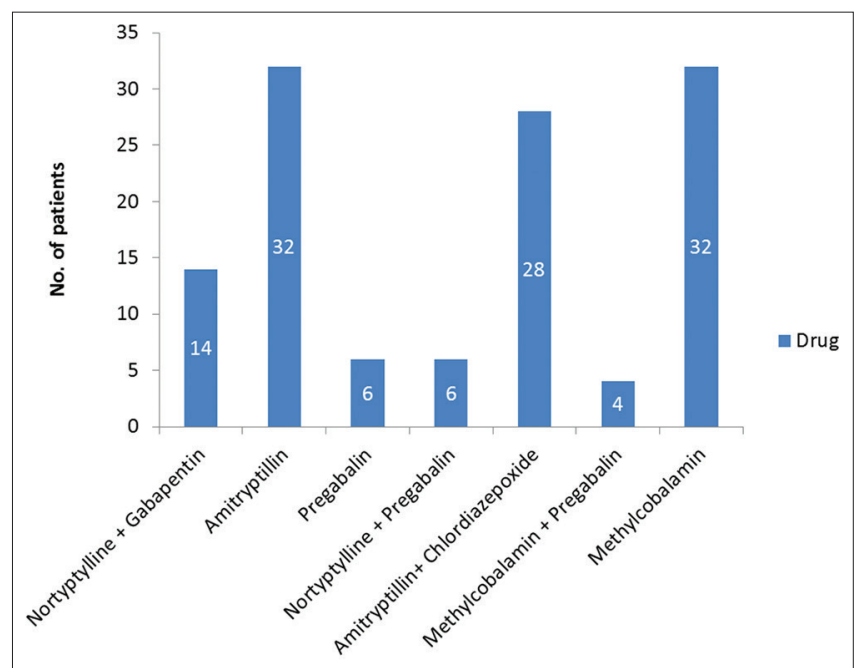

Figure 2: Distribution of prescribed drugs for the treatment of diabetic neuropathy 
combination(FDCs) of more than one drugs, the most common type being Amitryptillin (10mg) + Chlordiazepoxide $(12.5 \mathrm{mg})$ i.e. $28 \%$ followed by Nortryptylline $(10 \mathrm{mg})+$ Gabapentin (400mg)- 14\% [Figure-2].

All the FDCs were found to be branded version. Only 18\% patients received drugs in combination of branded as well as generic as advised in their prescription. The other drugs surprisingly observed to be prescribed for management of DN were ibuprofen (22\%) and paracetamol (35\%) respectively.

On assessing the average cost of therapy for the treatment of DN exclusively for a patient per day it was found to be around 9.55 1.20 INR considering both OPD and indoor patients together. The most expensive drug prescribed was FDC of Nortriptyline and Gabapentin costing around 23.73INR/tab. The cheapest drug administered was Amitriptyline costing around 1.15 INR per tablet. The cost analysis was done by taking reference from Drug Today ${ }^{\mathrm{TM}}$ (Apr-Jun 2017). The list of adverse effects of consumed drugs noted among the study population is mentioned in [Table-2].

List of adjuvant medications found in the prescriptions of patients receiving treatment from the Neuromedicine indoor and/or OPD were listed in [Table 3].

\section{DISCUSSION}

Diabetes mellitus is a chronic metabolic condition where the patients need a lifelong treatment. In spite of giving the best effort and having tight glycaemic control, patient still may develop neurological complications after some time which increases the morbidity and has a deep impact on the quality of life. This cross sectional, observational study was conducted in a tertiary care hospital in the eastern part of India to assess the pattern of drugs used for the treatment of diabetic neuropathy since there are diverse opinion and option for such treatment. A total of $(n=100)$ patients of either sex suffering from diabetic neuropathy for a period of more than six months attending the neurology OPD as well as admitted in the neurology ward were recruited in the study. Most of the study patients were female $(66 \%)$ and mostly homemaker. Most of the prescribed drugs were dispensed from the hospital pharmacy and few medicines were procured by the patients from the local pharmacy store. Thus, the out of pocket expenditure were minimum for the study patient. Unlike the recommendation of the American Academy of Neurology stating Pregabalin as a level A drug for the treatment of peripheral neuropathy our study revealed that the most preferred drug was Amitriptyline which is rather categorized as level B. ${ }^{12}$ The reason behind such finding may be due to the abundant hospital supply of Amitriptyline which the treating physician has to prescribe frequently. An interesting finding of this study was not a

Table: 1 Characteristic of peripheral diabetic
neuropathy in the study population

\begin{tabular}{|c|c|c|}
\hline Drug & $\begin{array}{l}\text { Adverse } \\
\text { Effect (s) }\end{array}$ & $\begin{array}{c}\text { Patients } \\
\text { experienced } \\
\text { effect (\%) }\end{array}$ \\
\hline \multirow{3}{*}{ Amitriptyline } & Dizziness & 33 \\
\hline & Dry mouth & 76 \\
\hline & Somnolence & 82 \\
\hline \multirow{4}{*}{ Nortyptilline+Gabapentin } & Dizziness & 35 \\
\hline & Somnolence & 16 \\
\hline & Dry mouth & 57 \\
\hline & Nausea & 4 \\
\hline \multirow[t]{2}{*}{ Pregabalin } & Dizziness & 45 \\
\hline & Somnolence & 12 \\
\hline \multirow[t]{2}{*}{ Nortyptilline+Pregabalin } & Dizziness & 24 \\
\hline & Somnolence & 15 \\
\hline
\end{tabular}

\begin{tabular}{|c|c|c|}
\hline Name of the drug & $\begin{array}{l}\text { ATC DDD } \\
\text { Classification }\end{array}$ & $\begin{array}{c}\text { No of } \\
\text { prescriptions } \\
\text { encountered }\end{array}$ \\
\hline Tab. Pantoprazole (40mg) & $\mathrm{A} 02 \mathrm{BC} 02$ & 33 \\
\hline Tab. Rabeprazole (20mg) & A02BC04 & 24 \\
\hline Tab. Ibuprofen (400mg) & MO1AE01 & 22 \\
\hline Tab. Antacid & $\mathrm{A} 02 \mathrm{AF}$ & 15 \\
\hline $\begin{array}{l}\text { Tab. Calcium } \\
\text { supplementation }\end{array}$ & A12AA & 42 \\
\hline Tab. Paracetamol (650mg) & NO2BE01 & 35 \\
\hline Cap. Multivitamins & A11AA04 & 12 \\
\hline
\end{tabular}

single incidence of switch over or alteration of drugs done for the treatment of neuropathy in patients of either group during the study period. Perhaps the physician preferred to stick to a particular regimen for a considerable period of time before modifying the management protocol which was not captured in this study due to its short span. Adverse drug reactions as reported by the study population are comparable with findings of other studies. ${ }^{13-15}$

Some analgesics like ibuprofen, paracetamol which has as such no role in the treatment of DN and is not recommended in any standard treatment guideline were prescribed to the patients. Other drugs like calcium supplementation or multivitamins prescribed to the patients has no as such therapeutic benefit for alleviation of neurological pain related to complication of diabetes 
mellitus. Since the study design had no provision of taking interview of the treating physician, it was difficult to put a comment on the justification of such drug prescribing behavior.

\section{CONCLUSION}

Management of diabetic neuropathy was not an easy task and therefore treating physicians tried various options. Most of these drugs had adverse effects which was evident from the patient's feedback. Treatment provided to the patient was supported by standard guidelines placed by competent authority.

\section{LIMITATIONS OF THE STUDY}

A small cohort of patients in a small sample size suffering from $\mathrm{DN}$ in a single tertiary care hospital was analyzed. Trend in the prescribing drug type/dose/frequency change or modification in a patient was not followed up due to the short duration of the study. Outcome of such treatment i.e. alleviation of pain or increase in the quality of life was not assessed in this study.

\section{ACKNOWLEDGEMENT}

The authors declare that there is no conflict of interests. The authors acknowledge the departmental staffs of Neuromedicine engaged in this study for their unconditional support in collection of data.

\section{REFERENCES}

1. Vinik Al. Peripheral neuropathy: pathogenesis and therapy. Am J Med 1999; 107(2B): 17S-26S.
2. Apfel SC. Introduction to diabetic neuropathy. Am J Med1999; 107 (Suppl): 1S-8S.

3. Harati Y. Diabetes and the nervous system. Endo Metab Clin North Am 1996; 25:325 -359.

4. Boulton AJM and Malik RA. Diabetic neuropathy. Med Clin North Am 1998; 82: 909-929.

5. Raman R, Gupta A, Krishna S, Kulothungan V and Sharma T. Prevalence and risk factors for diabetic microvascular complications in newly diagnosed type II diabetes mellitus. Sankara Nethralaya Diabetic Retinopathy Epidemiology and Molecular Genetic Study (SN-DREAMS, report 27) J Diabetes Complications 2012; 26:123-128.

6. Ashok S, Ramu M, Deepa R and Mohan V. Prevalence of neuropathy in type 2 diabetic patients attending a diabetes centre in South India. J Assoc Physicians India. 2002; 50:546-550.

7. D'Souza M, Kulkarni V, Bhaskaran U, Ahmed H, Naimish H and Prakash A, et al. Diabetic peripheral neuropathy and its determinants among patients attending a tertiary health care centre in Mangalore, India. J Public Health Res. 2015; 4: 450.

8. Srishyla MV, Krishnamurthy M, Nagarani MA, Andrade C and Venketaraman BV. Prescription audit in an Indian hospital setting using the DD concept. Indian J Pharmacol. 1994; 26: $23-28$.

9. World Health Organization. Teachers Guide to Good Prescribing. World Health Organization Department of Essential Drugs and Medicine Policy. Geneva: World Health Organization, Geneva: 2001.

10. World Health Organization. Introduction to Drug Utilization Research. World Health Organization. Geneva: 2003.

11. Ghosh B, Sengupta S, Bhattacharjee R, Pal S, Saha SP and Ganguly G, et al. Spectrum of peripheral neuropathy in Eastern India. J Indian Med Assoc. 2006; 104:168-170.

12. Busui RP, Boulton AJM, Feldman EL, Bril V, Roy F, Malik RA, et al. Diabetic Neuropathy: A Position Statement by the American Diabetes Association. Diabetes Care 2017; 40:136 - 154.

13. Saarto T, Wiffen PJ. Antidepressants for neuropathic pain. Cochrane Database Syst Rev 2007; (4): CD005454.

14. Wiffen PJ, McQuay HJ, Rees JE and Moore RA. Gabapentin for acute and chronic pain. Cochrane Database Syst Rev. 2005;(3): D005452.

15. VinikA. Clinical review: use of antiepileptic drugs in the treatment of chronic painful diabetic neuropathy. J Clin Endocrinol Metab. 2005; 90(8):4936-4945.

\footnotetext{
Authors Contribution:

PB- Concept, design of the study; SM- Data collection, manuscript preparation; AB- Concept, design, manuscript writing, statistical analysis; SMN- Critical review of the manuscript; $\mathbf{M N}$ - Critical review of the manuscript.

Work Attributed to: Department of Neuromedicine and Pharmacology, Calcutta Medical College, Kolkata, West Bengal, India

Orcid ID:

Dr. Arunava Biswas - (i) https://orcid.org/0000-0002-9676-3410

Source of Support: Nil, Conflict of Interest: None declared.
} 